\title{
Sympathetic Nerve Activity During Hypertension Produced by Vertebral Embolism
}

\author{
Yasumi Uchida, M.D., Kazuaki KamisaKa, M.D., \\ and Hideo Ueda, M.D.
}

SUMmary

Responses of the sympathetic nerves and the systemic arterial pressure to vertebral embolism were examined in rabbits anesthetized with $\alpha$-chloralose under artificial respiration and the following results were obtained:

1. Following vertebral embolism, the systemic arterial pressure increased moderately at first followed by a slight decrease, then increased to much higher levels and returned gradually to the control levels, and thereafter it decreased to lower levels than the controls.

2. The sympathetic discharge increased slightly and momentarily at the onset of hypertension (the phase of the first increase), decreased to lower levels than the control (the phase of decrease), then increased markedly (the phase of the second increase) and returned gradually to the control levels in most experiments under intact buffer nerves. The phase of the second increase corresponded nearly to the sccond rise in blood pressure. The phase of decrease in sympathetic discharge disappeared or became slight with repeating embolism or with elevating blood pressure to much higher levels. Also, it became slight or disappeared in most experiments done after resection of the buffer nerves.

3. Both rhythmical and non-rhythmical impulses were recorded from the renal nerves. The former responded to vertebral embolism in somewhat different fashion from the latter.

4. Following embolism, the afferent impulses from the right subclavian baroreceptor increased nearly in parallel with the arterial pressure.

It was concluded that the sympathetic nerve showed various discharge patterns in response to vertebral embolism. It was supposed that the phase of decrease in sympathetic discharge was mainly due to reflex inhibition by the buffer nerves and that the excitation patterns of the sympathetic nerve following vertebral embolism were determined by the following factors: magnitude of the sympathetic nerve excitation, sympatho-inhibitory action of the buffer nerves, reactivity of the target organs of the sympathetic nerves and the control levels of both sympathetic nerve activity and blood pressure.

\section{Additional Indexing Words:}

Renal and adrenal nerve activity Rhythmical and non-rhythmical impulses in the renal nerve Buffer nerve activity

From the Second Department of Internal Medicine, Faculty of Medicine, University of Tokyo, Tokyo.

Received for publication November 20, 1968. 
$I^{T}$

$T$ is a well-known evidence that anemic section of the brain stem at the certain levels results in a marked rise in blood pressure. ${ }^{3)}$ Neurogenic hypertension was produced by injecting the plastic beads into the vertebral artery. ${ }^{21}$ Renin activity and catecholamines increased following vertebral embolism. ${ }^{11}$ On the other hand, the sympathetic nerve showed various discharge patterns following vertebral embolism; its activity increased in some, whereas decreased in other experiments of our preliminary studies.

The present studies were undertaken to elucidate what mechanisms participated in various response patterns of the sympathetic nerve observed during hypertension produced by vertebral embolism.

\section{Methods}

Twenty-eight rabbits were examined for the present studies. The rabbits were anesthetized with $\alpha$-chloralose (100 $\mathrm{mg}$. $/ \mathrm{Kg}$. to $110 \mathrm{mg} . / \mathrm{Kg}$.) injected intravenously. The respiration was maintained with an endotracheal tube attached to a respirator pump. The rabbits were fixed at the supine position. The distal part of the right subclavian artery and its branches except the right vertebral artery were ligated. A polyethylene catheter was introduced through the right common carotid artery into the right subclavian artery. About $5 \mathrm{mg}$. of the plastic beads 50 to $80 \mu$. in diameter suspended in $0.1 \mathrm{ml}$. of Ringer's solution were injected through the catheter into the vertebral artery. The responses of the pressure were recorded by a Statham strain gauge connected to a catheter inserted into the right femoral artery. The left flank was opened and the renal and adrenal nerves of the left side were dissected from their surrounding tissues. They were divided into a few fibers in several, while not in other cases. The action potentials were led off from these nerves with small bipolar electrodes, amplified for display on an oscilloscope, and photographed. At the same time, an integrator unit was derived from the electroneurogram using a pulse-integrator and was recorded on a pen-oscillograph. The height of the tracing thus obtained indicated semiquantitatively the number of the impulses per second.

The changes in number of the impulses of the sympathetic nerves produced by the first vertebral embolism were examined under intact buffer nerves and after resecting them in 12 and 7 cases respectively.

The changes of the impulses during hypertension produced before and after resecting the buffer nerves were compared in 3 cases. Effects of repeating embolism on the impulses were examined in 11 cases with intact buffer nerves and after resection in 5 cases. In 4 cases, the rhythmical and non-rhythmical impulses were recorded separately and their responses to vertebral embolism were compared before and after resecting the buffer nerves.

The responses of the right subclavian baroreceptor to vertebral embolism were examined in 2 cases.

\section{Results}

Following vertebral embolism, the systemic arterial pressure increased 


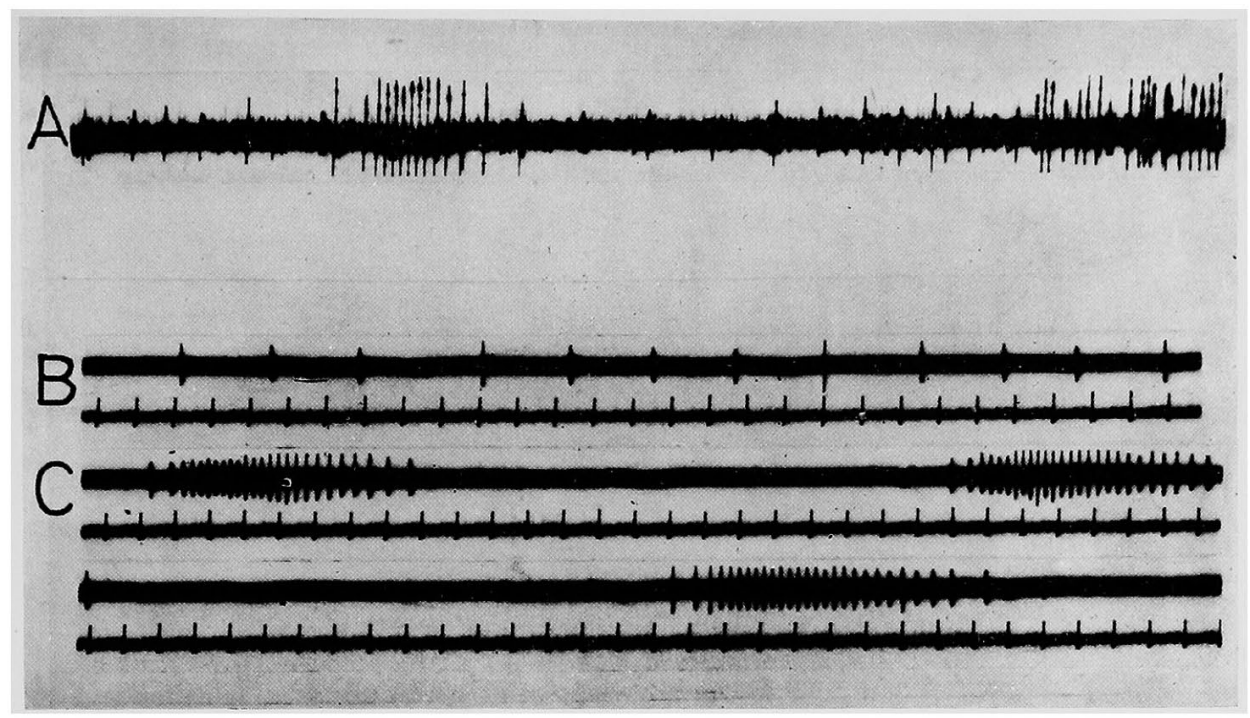

Fig. 1. The efferent impulses in the renal nerve. Rate of amplification differs by the recordings.

A: Both rhythmical and non-rhythmical impulses recorded during hypertension. The rhythmical impulses discharged continuously whereas the non-rhythmical large ones bursted sporadically.

B: the non-rhythmical impulses recorded after hypertension had subsided.

G: the non-rhythmical impulses selectively recorded during hypertension. They discharged repetitively but with no relation to respiration and e.k.g.

moderately at first followed by a slight decrease, then increased to much higher levels and thereafter returned gradually to the control levels in most experiments as shown in Fig. 2. The second rise in blood pressure became slight or disappeared with repeating embolism.

Two types of the impulses were recorded from the renal nerves in all cases; the ones of rhythmically discharging with the arterial pulsation and/or respiration, and the ones of much higher voltages and of not rhythmically discharging. Different from the rhythmical ones, the non-rhythmical impulses were scantily discharging before embolism. Usually, they appeared for the first time during hypertension produced by vertebral embolism. During hypertension, they discharged repetitively, but with no relation to the arterial pulsation and respiration as shown in Fig. 1. Moreover, they responded to vertebral embolism in somewhat different fashion from the rhythmical ones as will be explained elsewhere.

In most experiments in the present studies, the changes in number of the impulses of both types were recorded not separately and the data thus obtained are represented in Table I.

1. Responses of the sympathetic nerves to vertebral embolism under intact 


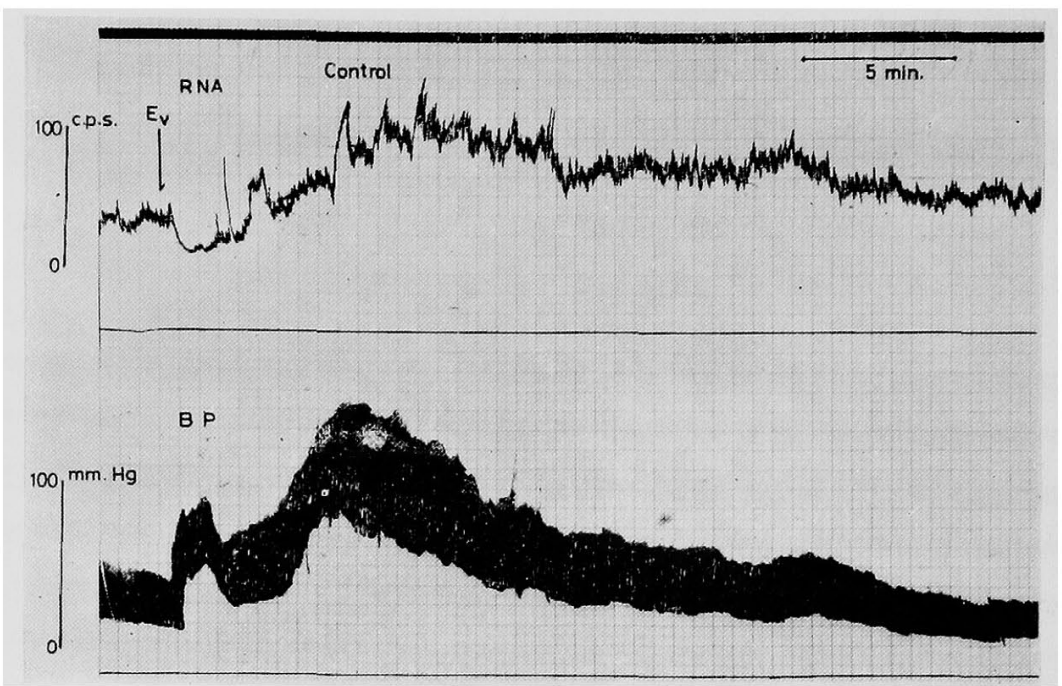

Fig. 2. The renal nerve activity during hypertension produced by vertebral embolism under intact buffer nerves.

RNA: renal nerve activity composed of both rhythmical and non-rhythmical impulses. BP: systemic arterial pressure.

$\mathrm{E}_{\nabla}$; vertebral injection of the plastic beads.

Following vertebral embolism, a slight increase followed by a decrease and a succeeding marked increase were observed in the renal nerve activity. The marked increase in renal nerve activity corresponded nearly to the second rise in the blood pressure.
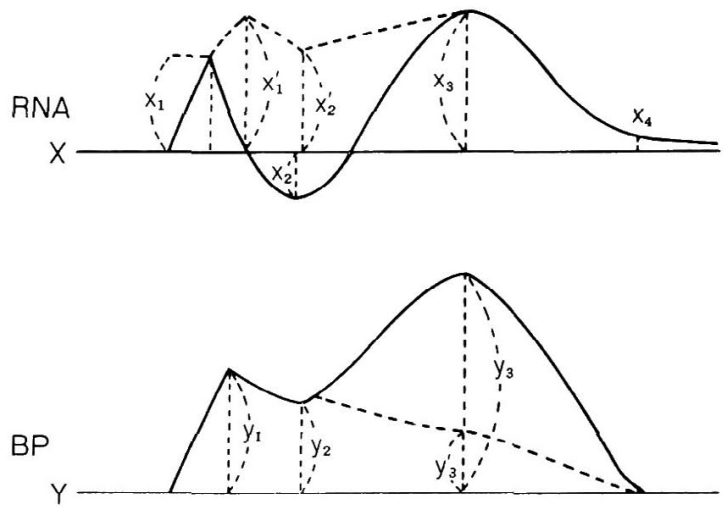

Fig. 3. X: the control level of sympathetic discharge (c.p.s.).

$\mathrm{Y}$ : the control level of mean arterial pressure $(\mathrm{mm} . \mathrm{Hg}$ ).

$\mathrm{x}_{1}$ and $\mathrm{x}_{1}{ }^{\prime}$ : the maximum changes in sympathetic discharge in the phase of the first increase.

$\mathrm{y}_{1}$ : the rise in blood pressure corresponding either to $\mathrm{x}_{1}$ or $\mathrm{x}_{1}{ }^{\prime}$.

$\mathrm{x}_{2}$ and $\mathrm{x}_{2}{ }^{\prime}$ : the maximum changes in sympathetic discharge during the phase of decrease.

$y_{2}$ : the rise in blood pressure corresponding either to $x_{2}$ or $x_{2}{ }^{\prime}$.

$\mathrm{x}_{3}$ : the maximum changes in sympathetic discharge in the phase of the second increase.

$\mathrm{y}_{3}$ and $\mathrm{y}_{3}{ }^{\prime}$ : the rise in blood pressure corresponding to $\mathrm{x}_{3}$.

$\mathrm{x}_{4}$ : the change in sympathetic discharge when the blood pressure returned to the control level $(\mathrm{Y})$. 
A. Under Intact Buffer Nerves

Table I.

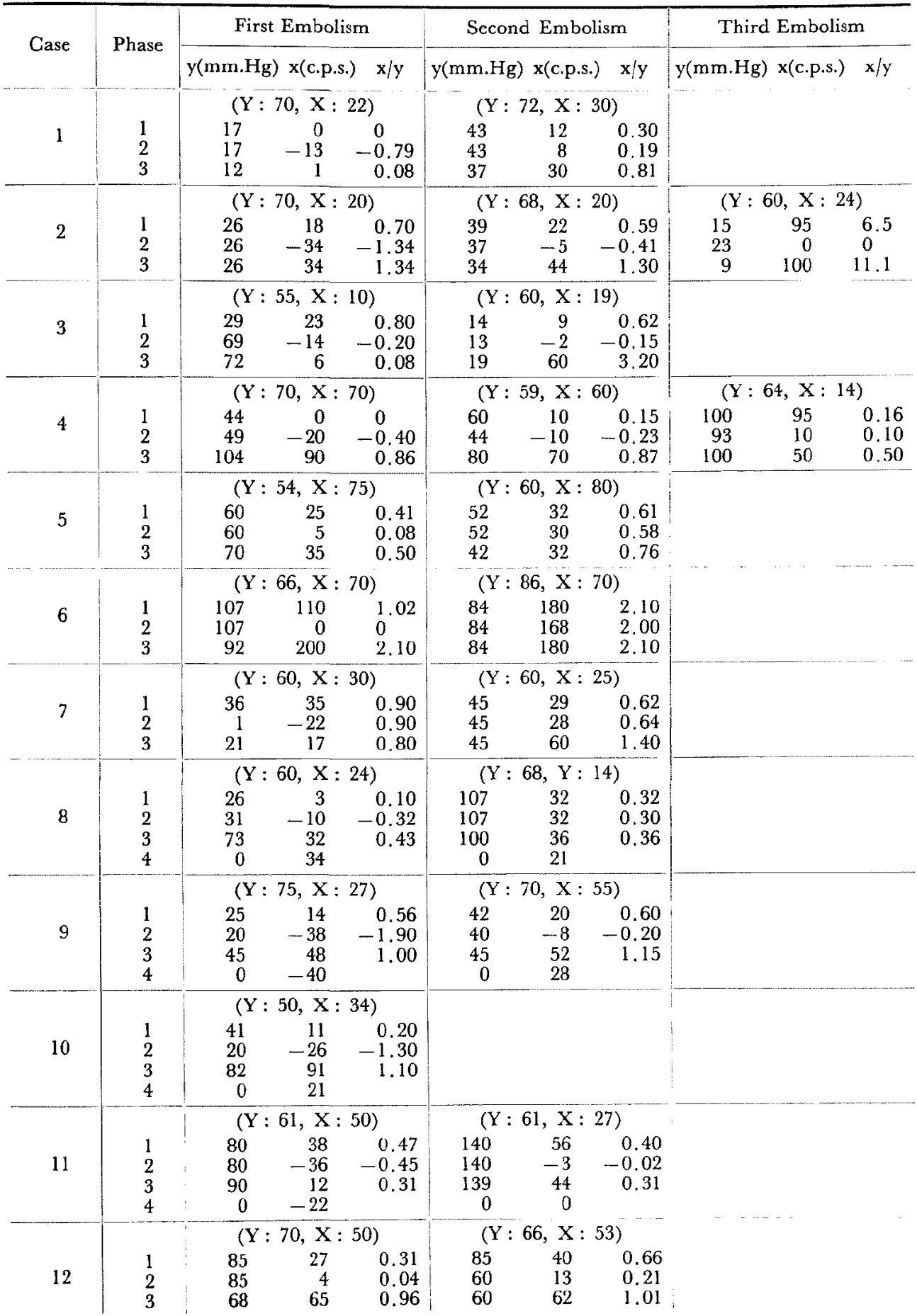


Table I. Continued

B. Effects of Resecting the Buffer Nerves

\begin{tabular}{|c|c|c|c|c|c|c|c|}
\hline \multirow{2}{*}{ Case } & \multirow{2}{*}{ Phase } & \multicolumn{3}{|c|}{ Before Resection } & \multicolumn{3}{|c|}{ After Resection } \\
\hline & & $y(\mathrm{~mm} . \mathrm{Hg})$ & $\mathrm{x}(\mathrm{c} . \mathrm{p} . \mathrm{s})$. & $x / y$ & $\mathrm{y}(\mathrm{mm} \cdot \mathrm{Hg})$ & x(c.p.s.) & $\mathrm{x} / \mathrm{y}$ \\
\hline 1 & $\begin{array}{l}1 \\
2 \\
3 \\
\end{array}$ & $\begin{array}{r}106 \\
93 \\
133 \\
\end{array}$ & $\begin{array}{r}100, X \\
0 \\
-50 \\
42 \\
\end{array}$ & 2) $\begin{array}{l}0 \\
-0.54 \\
0.31 \\
\end{array}$ & $\begin{array}{r}90 \\
90 \\
100 \\
\end{array}$ & $\begin{array}{c}58, X \\
35 \\
25 \\
61 \\
\end{array}$ & $\begin{array}{l}0.39 \\
0.28 \\
0.61 \\
\end{array}$ \\
\hline 2 & $\begin{array}{l}1 \\
2 \\
3\end{array}$ & $\begin{array}{l}26 \\
26 \\
37\end{array}$ & $\begin{array}{c}70, X: \\
15 \\
-25 \\
30\end{array}$ & $\begin{array}{r}0.59 \\
-0.96 \\
0.80\end{array}$ & $\begin{array}{r}21 \\
21 \\
8\end{array}$ & $\begin{array}{c}64, X: \\
43 \\
15 \\
100\end{array}$ & $\begin{array}{r}2.00 \\
0.70 \\
12.00\end{array}$ \\
\hline 3 & $\begin{array}{l}1 \\
2 \\
3\end{array}$ & $\begin{array}{l}34 \\
20 \\
20\end{array}$ & $\begin{array}{c}52, X: \\
13 \\
-15 \\
27\end{array}$ & $\begin{array}{r}0.39 \\
-0.75 \\
1.35\end{array}$ & $\begin{array}{r}12 \\
12 \\
8\end{array}$ & $\begin{array}{c}50, X: \\
60 \\
5 \\
50\end{array}$ & $\begin{array}{l}5.00 \\
0.41 \\
6.20\end{array}$ \\
\hline
\end{tabular}

G. After Resecting the Buffer Nerves

\begin{tabular}{|c|c|c|c|c|c|c|c|}
\hline \multirow{2}{*}{ Case } & \multirow{2}{*}{ Phase } & \multicolumn{3}{|c|}{ First Embolism } & \multicolumn{3}{|c|}{ Second Embolism } \\
\hline & & $y(\mathrm{~mm} \cdot \mathrm{Hg})$ & x(c.p.s.) & $\mathrm{x} / \mathrm{y}$ & $y(\mathrm{~mm} . \mathrm{Hg})$ & $x($ c.p.s. $)$ & $x / y$ \\
\hline 1 & $\begin{array}{l}1 \\
2 \\
3 \\
\end{array}$ & $\begin{array}{l}15 \\
15 \\
30 \\
\end{array}$ & $\begin{array}{c}60, X \\
28 \\
14 \\
60\end{array}$ & $\begin{array}{l}1.30 \\
0.60 \\
2.00\end{array}$ & $\frac{14}{10}$ & $\begin{array}{c}55, \mathrm{X} \\
\frac{22}{35}\end{array}$ & $\begin{array}{l}1.55 \\
3.50\end{array}$ \\
\hline 2 & $\begin{array}{l}1 \\
2 \\
3\end{array}$ & $\begin{array}{l}61 \\
28 \\
28\end{array}$ & $\begin{array}{c}60, x: \\
47 \\
0 \\
50\end{array}$ & $\begin{array}{l}0.77 \\
0 \\
1.80\end{array}$ & $\begin{array}{l}34 \\
26 \\
26\end{array}$ & $\begin{array}{c}55, X: \\
50 \\
35 \\
52\end{array}$ & $\begin{array}{l}1.44 \\
1.33 \\
2.00\end{array}$ \\
\hline 3 & $\begin{array}{l}1 \\
2 \\
3\end{array}$ & $\begin{array}{l}28 \\
72 \\
75\end{array}$ & $\begin{array}{c}65, \mathrm{X}: \\
55 \\
-1 \\
40\end{array}$ & $\begin{array}{r}2.00 \\
-0.01 \\
0.57\end{array}$ & $\begin{array}{l}34 \\
32 \\
32\end{array}$ & $\begin{array}{c}70, X: \\
44 \\
38 \\
60\end{array}$ & $\begin{array}{l}1.30 \\
1.19 \\
1.80\end{array}$ \\
\hline 4 & $\begin{array}{l}1 \\
2 \\
3\end{array}$ & $\begin{array}{l}160 \\
160 \\
160\end{array}$ & $\begin{array}{c}55, X \\
25 \\
0 \\
112\end{array}$ & $\begin{array}{l}0.15 \\
0 \\
0.70\end{array}$ & $\begin{array}{r}140 \\
60 \\
140\end{array}$ & $\begin{array}{c}50, x: \\
100 \\
75 \\
140\end{array}$ & $\begin{array}{l}0.71 \\
0.53 \\
0.85\end{array}$ \\
\hline 5 & $\begin{array}{l}1 \\
2 \\
3\end{array}$ & $\begin{array}{l}55 \\
55 \\
69\end{array}$ & $\begin{array}{c}69, X: \\
98 \\
39 \\
130\end{array}$ & $\begin{array}{l}1.80 \\
1.09 \\
1.90\end{array}$ & & & \\
\hline 6 & $\begin{array}{l}1 \\
2 \\
3\end{array}$ & $\frac{52}{52}$ & $\begin{array}{c}50, \mathrm{X}: \\
\frac{35}{35}\end{array}$ & $\frac{0.67}{0.67}$ & $\begin{array}{l}45 \\
42 \\
42\end{array}$ & $\begin{array}{c}50, \mathrm{X}: \\
50 \\
25 \\
30\end{array}$ & $\begin{array}{l}1.11 \\
0.60 \\
0.70 \\
\end{array}$ \\
\hline 7 & $\begin{array}{l}1 \\
2 \\
3\end{array}$ & $\begin{array}{l}70 \\
70 \\
77\end{array}$ & $\begin{array}{c}62, \mathrm{X}: \\
80 \\
79 \\
130\end{array}$ & $\begin{array}{l}1.14 \\
1.10 \\
1.70\end{array}$ & & & \\
\hline
\end{tabular}

These data were calculated from the recordings. The values of the impulses are of semiquantitative ones,

$X$ : control value in number of the impulses per sccond (c.p.s.).

$\mathrm{Y}$ : control value of mean blood pressure (mm.Hg).

$x$ : change in number of the impulses (c.p.s.).

$y$ : change in mean blood pressure (mm.Hg).

For example, $x$ in the line of 2 shows the maximum change in number of the impulses during the phase of decrease $\left(\mathrm{x}_{2}\right)$. 


\section{buffer nerves}

The sympathetic discharge composed of both rhythmical and nonrhythmical impulses increased slightly at the onset of hypertension (the phase of the first increase) and decreased or disappeared thereafter (the phase of decrease), then increased markedly (the phase of the second increase) and returned gradually to the control levels in most experiments (Fig. 2). In Fig. $3, \mathrm{x}_{1}$ and $\mathrm{x}_{3}$ represent the maximum increases in sympathetic discharge in the phases of the first and second increase respectively and $x_{2}$ shows the maximum change in the phase of decrease, while $y_{1}, y_{2}$ and $y_{3}$ represent the changes in the blood pressure corresponding to $\mathrm{x}_{1}, \mathrm{x}_{2}$ and $\mathrm{x}_{3}$ respectively.

The phase of the first increase was produced by the first embolism in 10 of 12 cases, but by the second in all 11 cases. The first increase $\left(x_{1}\right)$ in the second embolism was larger than that in the first in 9 of 11 cases. The phase of decrease was produced by the first embolism in all 12 cases, the number of the impulses in this phase was less than the control (X) and accordingly $\mathrm{x}_{2}$ was minus in 9 of 12 cases. However, this phase became obscure or disappeared with repeating embolism in all cases as shown in Fig. 4 and Table I, and the number of the impulses in this phase of the second embolism was less than the control in only 5 of 11 cases.

The second increase $\left(\mathrm{x}_{3}\right)$ produced by the second embolism was larger than that produced by the first in 9 of 11 cases. Additionally, $x_{3} / y_{3}$ in which $y_{3}$ represents the rise in mean blood pressure corresponding to $x_{3}$ was larger

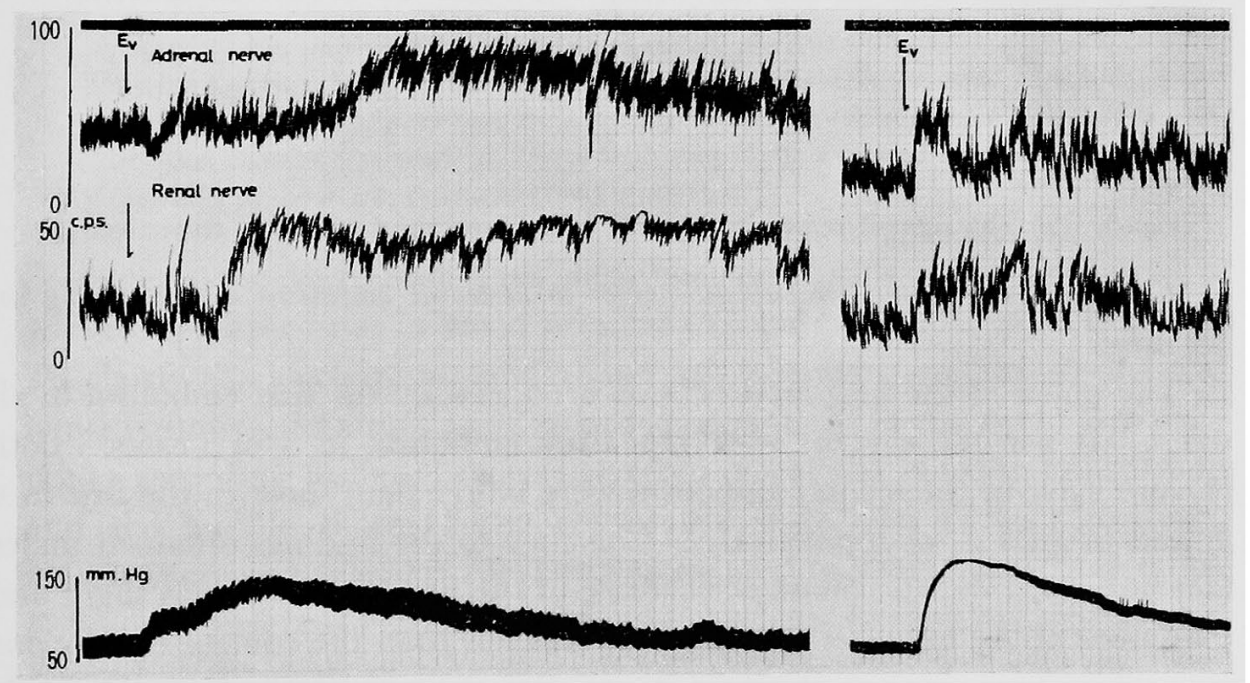

Fig. 4. The simultaneous recordings of renal and adrenal nerve activities during hypertension produced by vertebral embolism under intact buffer nerves. The phase of decrease was observed in the recordings of the left side (first embolism), whereas it was not in the recordings of the right side (second embolism). 
in the second embolism than that in the first in 9 of 11 cases. Also, $x_{1} / y_{1}$ and $\mathrm{x}_{2} / \mathrm{y}_{2}$ in the second embolism were larger than those in the first in 9 of 11 and in all 11 cases respectively (Table $I$ ). The parameters $x_{1} Y / y_{1} X$ and $x_{3} Y / y_{3} X$ increased with repeating embolism in most cases as shown in Fig. 5, presumably indicating that the reactivity of the target organs of the sympathetic nerves was reduced with repeating embolism.

The response patterns were compared before and after resection of the carotid sinus, aortic nerves and cervical vagi in the same 3 cases. The first increase $\left(\mathrm{x}_{1}\right)$ and the second $\left(\mathrm{x}_{3}\right)$ produced after resecting the nerves were larger than those produced before resection in all cases. The phase of decrease became slight and $\mathrm{x}_{2}$ was changed from minus to plus after resecting the buffer nerves in all 3 cases (Table I).

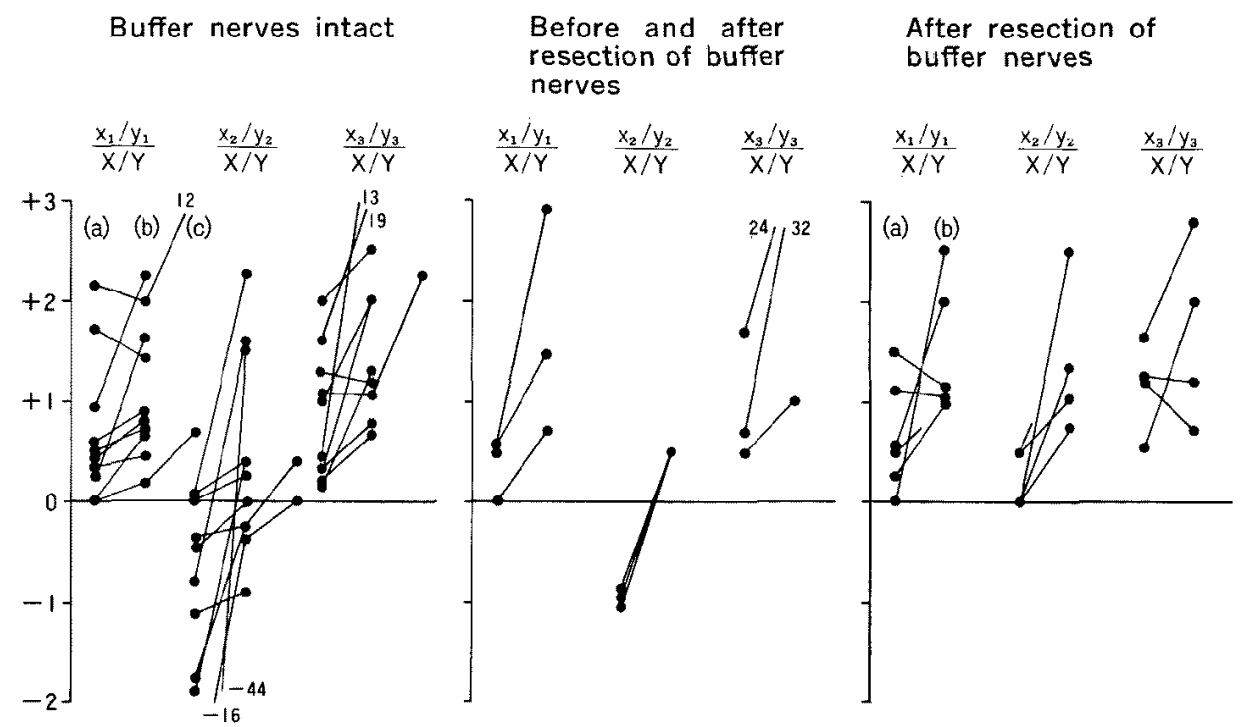

Fig. 5. (a), (b) and (c) represent the first, second and third embolism respectively.

2. Responses of the sympathetic nerves to vertebral embolism after resecting the buffer nerves

The phase of the first increase was produced by the first embolism in all 7 cases. It became evident with repeating embolism in 3 of 5 cases. Both $x_{1} / y_{1}$ and $x_{3} / y_{3}$ in the second embolism were larger than those in the first in 4 of 5 and in all 5 cases respectively. Contrary to the findings obtained under intact buffer nerves, the phase of decrease in the first embolism was slight and the number of the impulses in this phase was less than the control in only one case. This phase was not observed in one case as shown in Fig. 6 and Table I.

3. Responses of the rhythmical and non-rhythmical impulses to vertebral embolism As shown in Table I and Fig. 7, the first embolism produced only a 


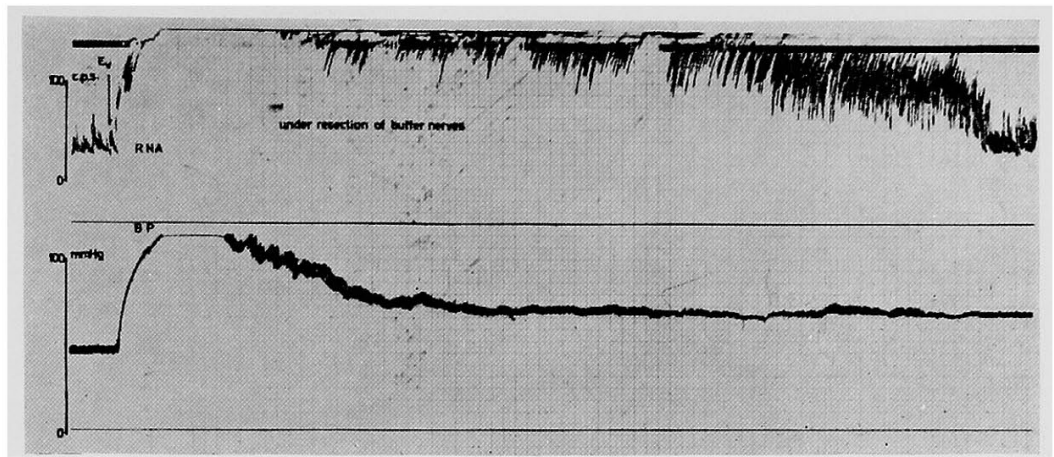

Fig. 6. Renal nerve discharge composed of both rhythmical and non-rhythmical impulses during hypertension produced by the first embolism after resecting the buffer nerves. The phase of decrease was not observed in this case.

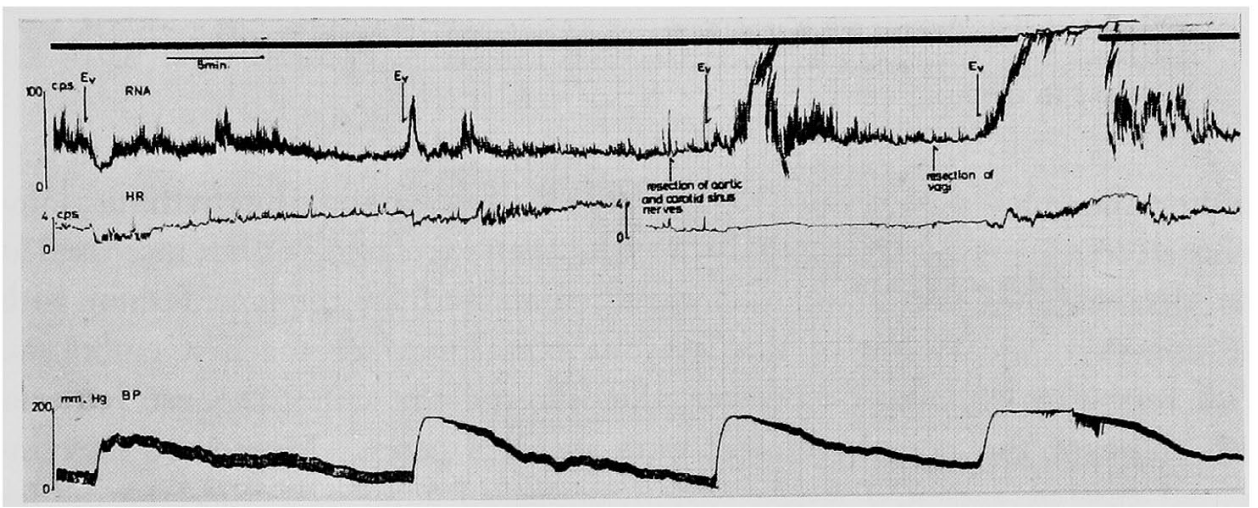

Fig. 7. Effects of resecting the buffer nerves and repeating embolism on sympathetic nerve activity. From the left to right: sympathetic discharge was decreased by the first embolism; it increased slightly in the second; it increased markedly in the third produced after resecting the carotid sinus and aortic nerves, although the rise in blood pressure was nearly the same with that in the second; it increased much more markedly in the fourth produced after vagotomy.

decrease in the discharges of the multifiber preparations of sympathetic nerve, whereas a marked rise in blood pressure in some cases with intact buffer nerves. To clarify the mechanisms underlying this phenomenon, the rhythmical and non-rhythmical impulses were recorded separately in the same 4 cases. The upper recording in Fig. 8 shows the responses of the non-rhythmical impulses and the middle those of the rhythmical ones. In these recordings, the former increased whereas the latter decreased following vertebral embolism. Following vertebral embolism, the non-rhythmical impulses appeared or increased at the onset of hypertension and disappeared or decreased thereafter and then reappeared or again increased in all 4 cases before resecting the buffer nerves. After resecting the buffer nerves in these cases, however, the nonrhythmical impulses continued to increase during hypertension and did not 


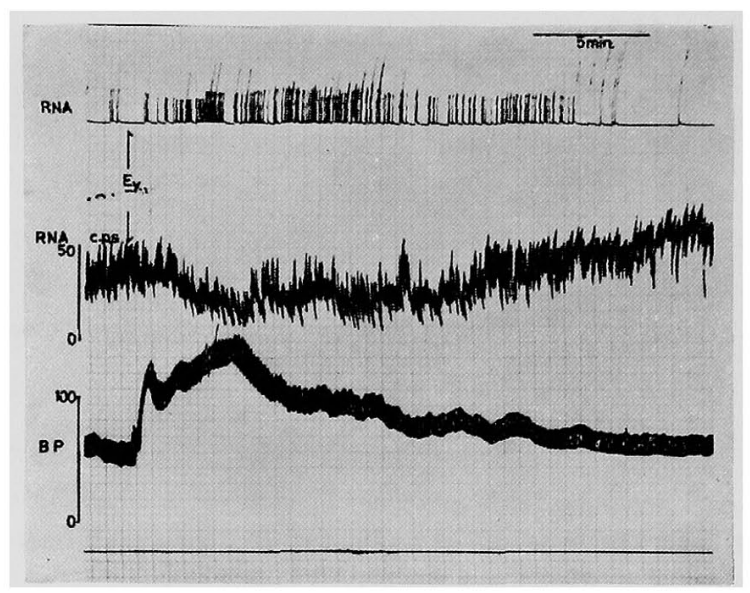

Fig. 8. The upper recording shows the changes in the non-rhythmical impulses and the middle shows the changes in the rhythmical ones. Following vertebral embolism, the rhythmical impulses decreased, whereas the non-rhythmical ones increased in this case.

produce the phase of decrease (Fig. 9). On the other hand, the rhythmical impulses decreased in 2; decreased at first and then increased in one; increased at first, decreased thereafter and then increased markedly in the same fashion with the non-rhythmical ones in the last one case following the first embolism. With repeating embolism, however, they showed the same response patterns with those of the non-rhythmical ones in all 4 cases. Moreover, they increased during repeated hypertension produced after resecting the buffer nerves in 3 cases.

The small fluctuations of the blood pressure observed during hypertension

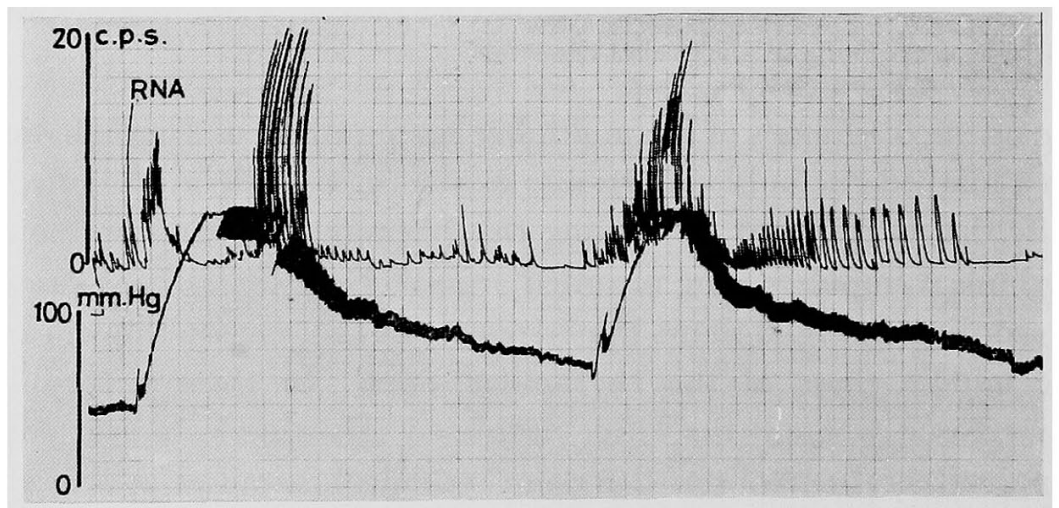

Fig. 9. Selective recordings of the non-rhythmical impulses before and after resecting the buffer nerves. The non-rhythmical ones increased at the onset of hypertension, decreased thereafter (the phase of decrease) and increased again following embolism produced under intact buffer nerves (left). While, the phase of decrease was not observed during hypertension produced after resecting the buffer nerves (right). 


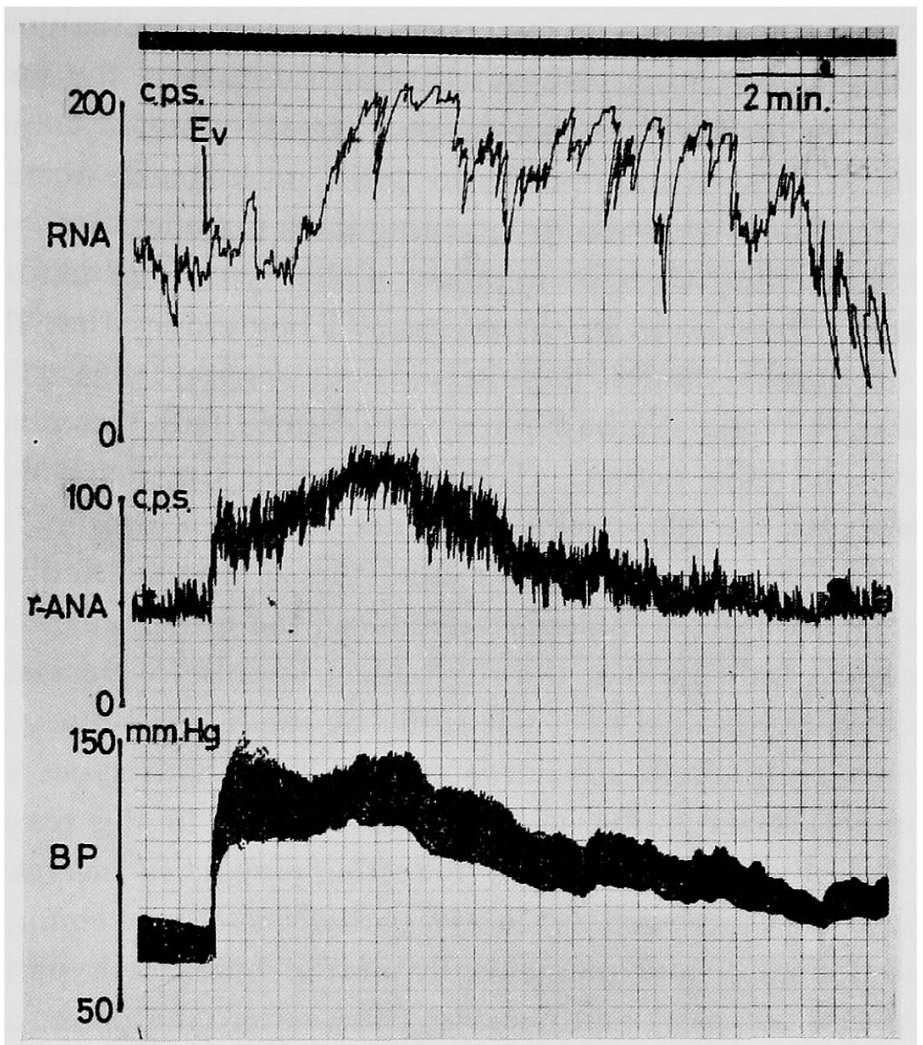

Fig. 10. The impulses from the right subclavian baroreceptor recorded simultaneously with those of the renal $^{\text {n }}$ nerve. The impulses were changed nearly in parallel with the blood pressure.

r-ANA: right aortic nerve activity.

related closely to the burst of the non-rhythmical impulses. The blood pressure rose up soon after the appearance of the burst and then decreased gradually until the next came.

\section{Responses of the buffer nerves to vertebral embolism}

The afferent impulses from the right subclavian baroreceptor were recorded simultaneously with the impulses of the renal nerve in 2 cases. As shown in Fig. 10, they increased at first and then returned to the control level nearly in parallel with the arterial pressure.

\section{Discussion}

The findings that the non-rhythmical impulses which were scarcely observed before appeared or increased, whercas the rhythmical ones decreased during hypertension produced by the first embolism under intact buffer nerves 
and that the former related closely to the small fluctuations in blood pressure during hypertension support the possibility that the former played the major role in producing hypertension. The rhythmical impulses, which decreased during hypertension produced under intact buffer nerves, increased during hypertension produced after resecting them in some cases. This finding supports the possibility that the impulses of this type were inhibited reflectingly by the buffer nerves in these cases. The finding that the phase of decrease in the non-rhythmical impulses was not observed during hypertension produced after resecting the buffer nerves indicates that this phase was also produced by the buffer nerves. The findings that the rhythmical impulses decreased whereas the non-rhythmical ones increased during hypertension produced under intact buffer nerves and the additional findings that the intravenous injection of norepinephrine reduced the former markedly whereas the latter scarcely indicate that the rhythmical impulses were easily inhibited whereas the non-rhythmical ones not easily by the buffer nerves.

Decreased sympathetic discharge composed of both types in some experiments under intact buffer nerves might be due to the reason that the number of the rhythmical impulses reflectingly reduced overcame that of non-rhythmical ones increased. The sympathetic discharge composed of both types increased slightly and momentarily at the onset of hypertension (the phase of the first increase) and decreased thereafter (the phase of decrease), then increased markedly (the phase of second increase) and returned gradually to the control levels in most experiments. The phase of decrease which suc-

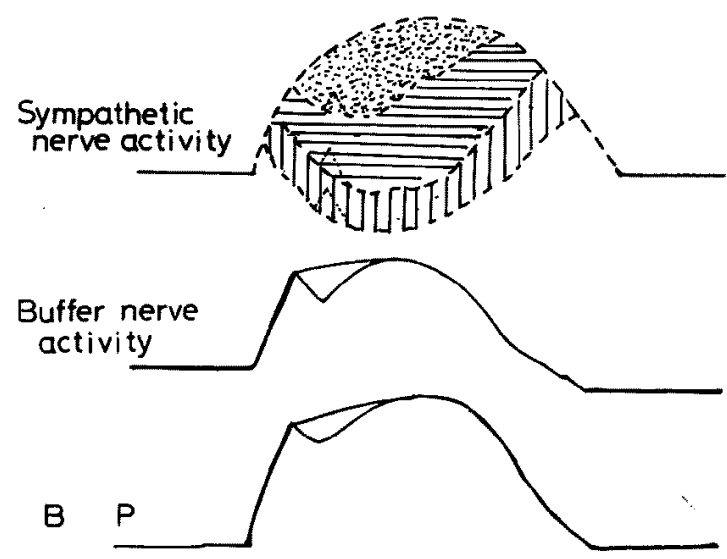

Fig. 11. Schematic representation of the sympathetic nerve activity during hypertension produced by vertebral embolism under intact buffer nerves. The sympathetic nerve activity is reduced by the sympatho-inhibitory action of the buffer nerves, producing the phase of decrease. This phenomenon may be called "Peace-meal phenomenon" of the sympathetic nerve activity produced by the buffer nerves. 
ceeded to the phase of the first increase was marked in the first embolism before resecting the buffer nerves, but it was slight or not observed even in the first embolism after resecting the nerves, indicating that the buffer nerves participated in producing the phase of decrease. It is a well known evidence that the buffer nerves inhibit the sympathetic nerve activity. Fig. 11 represents a schema of sympathetic nerve activity during hypertension produced by vertebral embolism. The occurrence of the phase of decrease can bc called "Peace-meal phenomenon" of sympathetic nerve activity produced by the buffer nerves. Fig. 12 shows the possible mechanisms for producing the

(A)
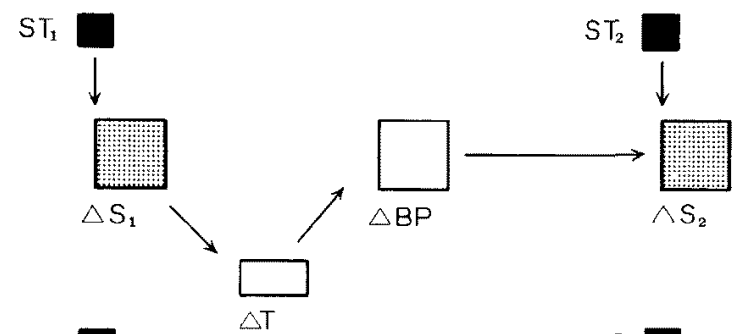

(B)
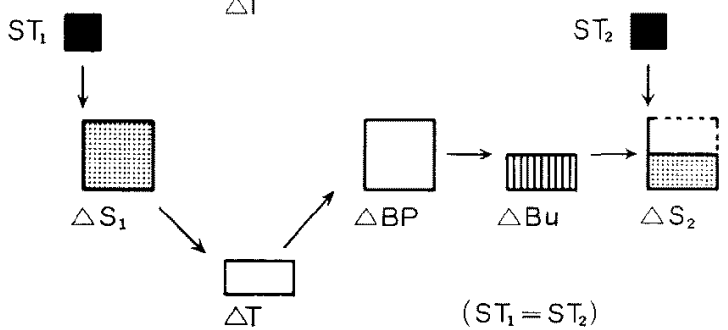

Fig. 12. Schematic representation of the possible mechanisms for the phase of decrease. The anoxia produced by the emboli is considered to be repetitive stimuli for the sympathetic nerve. To explain the mechanisms simply, only the succeeding two stimuli $\mathrm{ST}_{1}$ and $\mathrm{ST}_{2}$ were picked up and the level of the blood pressure before applying the stimuli was not taken into account.

phase of decrease. The anoxia produced by the emboli is considered to be the repetitive stimuli for the sympathetic nerve. To explain the mechanisms simply, only the succeeding two stimuli $\mathrm{ST}_{1}$ and $\mathrm{ST}_{2}$ were picked up and the level of the blood pressure before application of the stimuli was not taken into account in this figure. An increase in the sympathetic nerve activity $\left(\Delta \mathrm{S}_{1}\right)$ produced by a certain stimulus $\left(\mathrm{ST}_{1}\right)$ produces in turn a rise in blood pressure $(\Delta \mathrm{BP})$ by exciting its target organs $(\Delta \mathrm{T})$. Another stimulus $\left(\mathrm{ST}_{2}\right)$ which is the same with $\left(\mathrm{ST}_{1}\right)$ and is applied a moment later produces another increase in sympathetic nerve activity $\left(\Delta \mathrm{S}_{2}\right)$ which is of the same magnitude with $\left(\Delta \mathrm{S}_{1}\right)$ under complete ablation of the buffer mechanisms (A). Under the intact buffer mechanisms. (B), on the contrary, an increase in the buffer nerve activity $(\triangle \mathrm{Bu})$ produced by the preceding rise in blood pressure $(\Delta \mathrm{BP})$ reduces 
the next increase in sympathetic nerve activity $\left(\Delta \mathrm{S}_{2}\right)$ produced by $\left(\mathrm{ST}_{2}\right)$. Thus, $\left(\Delta \mathrm{S}_{2}\right)$ becomes smaller than $\left(\Delta \mathrm{S}_{1}\right)$ although the two stimuli are of the same magnitude.

Fig. 13 also shows the possible mechanisms played a role in producing or diminishing the phase of decrease in sympathetic nerve activity during hypertension produced by vertebral embolism. The levels of the blood pressure before applying the stimuli were taken into account in this figure. An increase in sympathetic nerve activity $\left(\Delta \mathrm{S}_{1}\right)$ produced by a stimulus $\left(\mathrm{ST}_{1}\right)$ results in a rise in blood pressure $(\triangle \mathrm{BP})$. The rise in blood pressure thus produced produces in turn an increase in buffer nerve activity $(\Delta \mathrm{Bu})$. The relationship between the rise in blood pressure and the increase in buffer nerve activity is represented by a sigmoid pressure-characteristics curve (Fig. 13a). The amount of sympatho-inhibitory effect by the buffer nerves is represented by $(\mathrm{k} \Delta \mathrm{Bu})$ in which $\mathrm{k}$ indicates a coefficient. The coefficient may differ by the fibers of the sympathetic nerve. For example, $\mathrm{k}$ of the rhythmical impulse is considered to be larger than that of the non-rhythmical one because the former in our present studies was more susceptible to the buffer nerves than the latter. In Fig. 12, 13 and $14, \mathrm{k}$ is considered to be 1 , and therefore, $(\mathrm{k} \Delta \mathrm{Bu})$ is the same with $(\Delta \mathrm{Bu})$. It can easily be understood from the pressure-characteristics curve that the increase in buffer nerve activity $(\Delta \mathrm{Bu})$ produced by the rise in blood pressure $(\Delta \mathrm{BP})$ and accordingly $(\mathrm{k} \Delta \mathrm{Bu})$ differ by the control levels of the blood pressure. An increase in buffer nerve activity
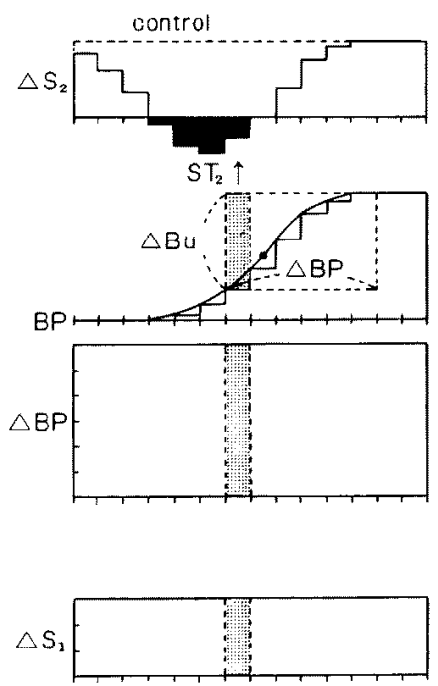

$S T_{1} \uparrow(a)$
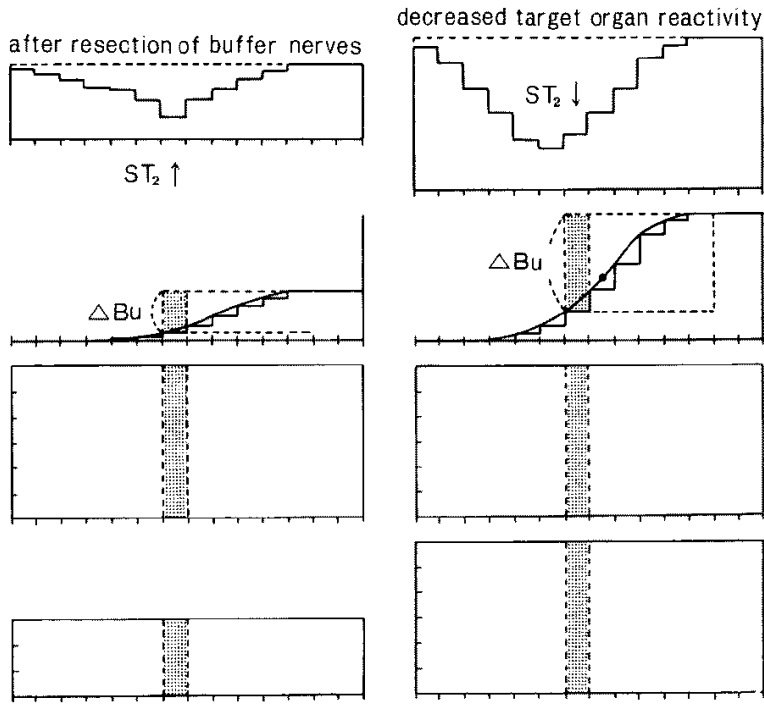

$S T_{1} \uparrow(b)$

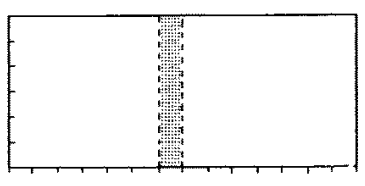

$\mathrm{ST}_{1} \uparrow(\mathrm{c})$

Fig. 13. Schematic representation of the possible mechanisms for the phase of decrease. These schemata are minutely explained elsewhere. 
$(A \mathrm{Bu})$ thus produced antagonizes with the next stimulus for sympathetic nerve $\left(\mathrm{ST}_{2}\right)$ applied a moment later and reduces the response of the sympathetic nerve to $\left(\mathrm{ST}_{2}\right)$. It is clear from the curve that $(\mathrm{k} \Delta \mathrm{Bu})$ produced by $(\Delta \mathrm{BP})$ can exceed $\left(\Delta \mathrm{S}_{1}\right)$ in a certain range of the control blood pressure, if $\left(\Delta \mathrm{S}_{1}\right)$ does not exceed the total sympatho-inhibitory effect $(\mathrm{kBu})$ by the buffer nerves. In this range of blood pressure where $(\mathrm{k} \Delta \mathrm{Bu})$ overcomes $\left(\Delta \mathrm{S}_{1}\right),\left(\Delta \mathrm{S}_{2}\right)$ produced by $\left(\mathrm{ST}_{2}\right)$ becomes negative, therefore the sympathetic nerve activity at the moment $\left(\mathrm{ST}_{2}\right)$ is applied is reduced to lower levels than the control.

The phase of decrease in sympathetic nerve activity became slight and the number of the impulses necessary to attain the same rise in blood pressure $\left(x_{1} / y_{1}\right.$ and $\left.x_{3} / y_{3}\right)$ increased with repeating embolism. The latter finding indicates that the reactivity of the target organs of sympathetic nerves was reduced by repeating embolism. Fig. 12c shows the possible mechanism played a role in diminishing the phase. In repeated cases, $\left(\Delta \mathrm{BP} / \Delta \mathrm{S}_{1}\right)$ and $\left(\mathrm{k} \Delta \mathrm{Bu} / \Delta \mathrm{S}_{1}\right)$ decrease because of the decreased target organ reactivity. Thus, $\left(\Delta \mathrm{S}_{2}\right)$ produced by $\left(\mathrm{ST}_{2}\right)$ becomes positive more easily and the sympathetic nerve activity at the moment $\left(\mathrm{ST}_{2}\right)$ is applied increases more easily to higher levels than the control as in the case of buffer nerve resection (Fig. 13b). Therefore, the phase of decrease disappears apparently when the reactivity of the target organs is much reduced. Likewise, $\left(\Delta \mathrm{S}_{2}\right)$ becomes positive and the sympathetic nerve activity increases to higher levels than the control if the increase in sympathetic nerve activity $\left(\Delta \mathrm{S}_{1}\right)$ is large enough to overcome the total sympathoinhibitory effect by the buffer nerves (kBu) even in the first embolism (Fig. 14b).

These mechanisms postulated above may enable to explain partly the various patterns of sympathetic nerve activity during hypertension produced by vertebral embolism.

The phase of decrease, although slight, was observed even after resecting the carotid sinus, aortic nerves and cervical vagi in most cases. It is supposed that the other buffer routs remained and played a role in producing the phase in these cases.

The blood pressure began to rise before the sympathetic nerve activity increased in a few cases. This rise in blood pressure was probably due to the increased peripheral resistance produced mechanically by the emboli. The plastic beads injected into the abdominal aorta more peripheral than the origin of the renal arteries produced a rise in blood pressure, while a decrease in sympathetic nerve activity (Fig. 15).

A mechanically induced rise in blood pressure by the emboli and a succeeding reflex decrease in sympathetic nerve activity might participate besidcs. the mechanisms explained elsewhere in the absence of the phase of the first increase observed in several experiments. 

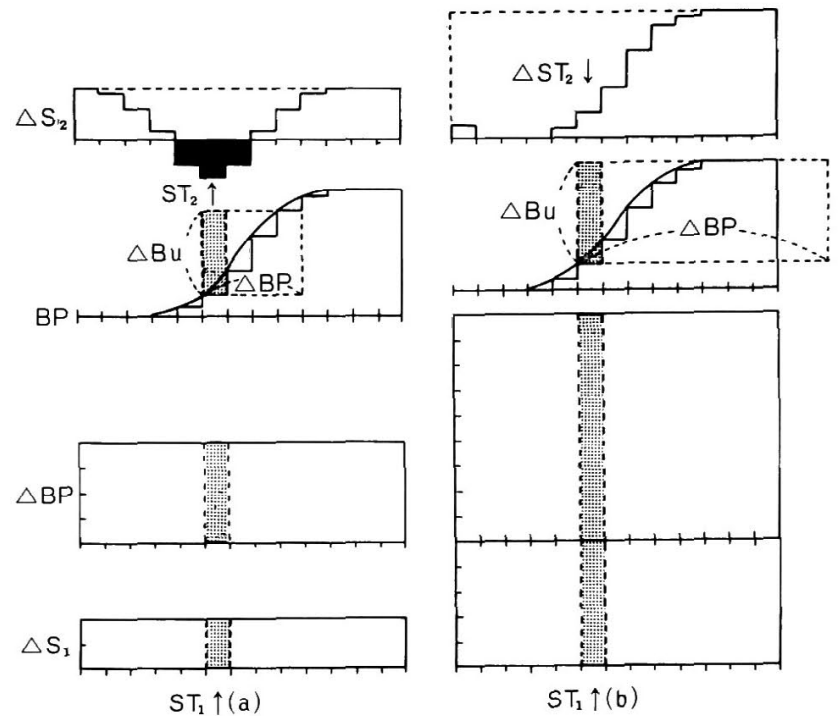

Fig. 14. Schematic representation of the possible mechanisms involved in sympathetic nerve activity during hypertension.

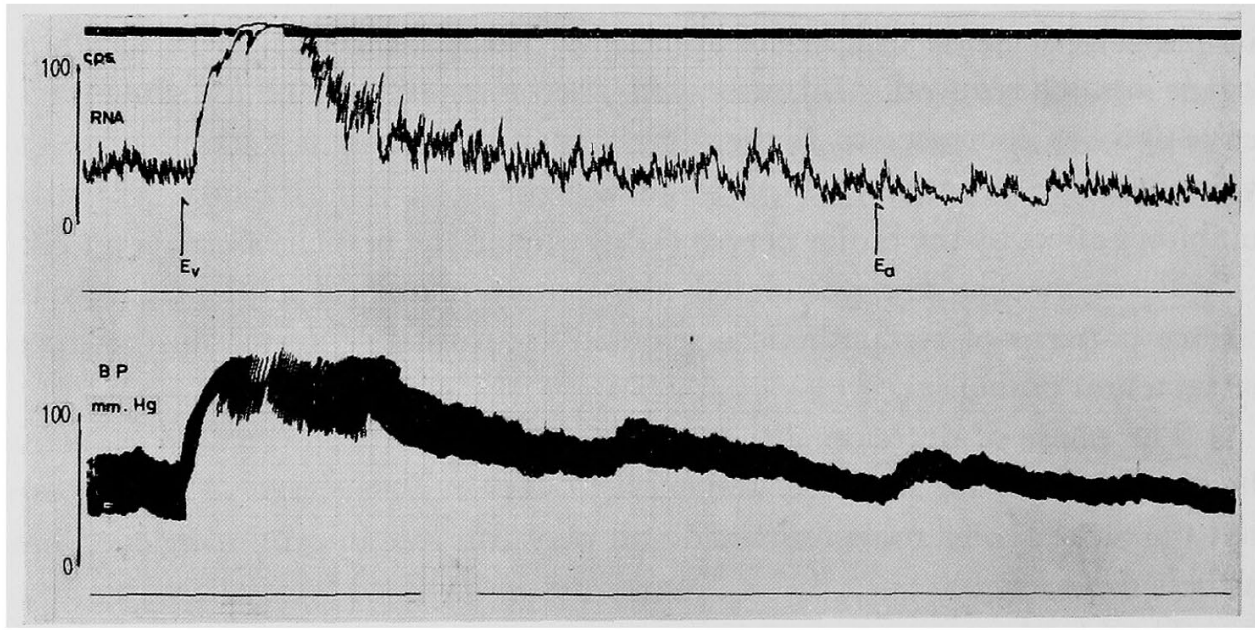

Fig. 15. Responses of the sympathetic nerve and systemic arterial pressure to the injections of plastic beads into the vertebral artery and abdominal aorta. The pressure was elevated both by vertebral and aortic injections. The sympathetic nerve activity increased following vertebral injection, whereas decreased following aortic injection. $\mathrm{E}_{\nabla}$ : vertebral injection. $\mathrm{E}_{\mathrm{a}}$ : aortic injection.

\section{REFERENCES}

1. Katsuki, S., et al.: Jap. Girculat. J. 31: 1956, 1967.

2. Ueda, H. and Uchida, Y.: Jap. Circulat. J. 31: 1283, 1967.

3. Uramoto, R.: Igaku Kenkyu 26: 1611, 1956. 